\title{
The therapeutic importance of home blood pressure assessment and combination antihypertensive therapy for achieving target blood pressure control: Ibaraki hypertension assessment trial
}

\author{
Akira Sato ${ }^{1}$, Shigeyuki Watanabe ${ }^{1}$, Shinji Okubo ${ }^{2}$, Toru Toi ${ }^{3}$, Toshiki Doi ${ }^{4}$, Hideaki Nakano ${ }^{5}$, Junichi Tada ${ }^{6}$ \\ and Kazutaka Aonuma ${ }^{1}$, for the I-HAT investigators
}

Tight blood pressure (BP) control is important for the prevention of cardiovascular disease in hypertensive patients. A cross-sectional study of 2339 patients from 101 clinics and hospitals in Ibaraki Prefecture was performed to evaluate BP control with the patients' current antihypertensive medication. Group $A(n=892)$ included high-risk hypertensive patients with at least one of the following risk factors: diabetes mellitus, chronic kidney disease or a history of myocardial infarction. Group B $(n=586)$ included patients $<65$ years old and Group C $(n=859)$ included patients $\geqslant 65$ years old. Both groups $B$ and $C$ included hypertensive patients without the above risk factors. A mean of $1.8 \pm 1.0$ antihypertensive drugs per patient were prescribed. A total of $35.8 \%$ of all patients received monotherapy, $40 \%$ received a combination of three therapies and $20.3 \%$ received more than three kinds of drugs. The percentage of patients achieving the target BP at the office and at home was significantly higher in Group $C$ than in the other groups $(P<0.001)$. A combination of more than two antihypertensive drugs, including a high dose of either an angiotensin receptor blocker or a calcium channel blocker, was frequently prescribed to Group A to achieve the target office BP. Although the target BP should be lower in Group A (given their comorbidities), the absolute BP value and the number of medications were similar to the other groups. In conclusion, we demonstrated that physicians should treat hypertension more intensively with a combination of more than two antihypertensive drugs, using a high dose to achieve the target BP. In addition, it is important to teach hypertensive patients the clinical importance of monitoring their BP at home and the need to achieve home BP targets.

Hypertension Research (2010) 33, 1264-1271; doi:10.1038/hr.2010.175; published online 7 October 2010

Keywords: antihypertensive drug; blood pressure control; combination therapy

\section{INTRODUCTION}

Hypertension is a globally important lifestyle-related disease because of its high incidence and concomitant risk of cardiovascular disease. ${ }^{1-4}$ It is estimated that in Japan alone, there are 40 million hypertensive patients, and by 2025 , there will be 1.56 billion people globally with the disease. ${ }^{5,6}$ On the other hand, it has been demonstrated that the risk of cardiovascular disease has decreased in correlation with improvements in blood pressure (BP) control associated with the use of hypertensive medicine. ${ }^{7-9}$ Therefore, to reduce the worldwide incidence of hypertensive complications, it is necessary to intensively control BP. Such control of hypertension requires reliable BP measurement. One problem that has been identified with the measurement of BP is the masked hypertension (MHT). In MHT, BP is lower in clinical measurements than during ambulatory monitoring. MHT has been shown to be associated with a high risk of cardiovascular disease similar to that associated with poor control of office BP. ${ }^{10,11}$ It has been shown that home BP measurement has a better prognostic accuracy than office BP measurement, ${ }^{12,13}$ and therefore, achieving target home BP control is of both clinical interest and therapeutic importance. The Japanese Society of Hypertension (JSH) Guidelines 2009 recommend the following target BP values in patients with diabetes mellitus (DM), chronic kidney disease (CKD) and previous myocardial infarction: office $\mathrm{BP},<130 / 80 \mathrm{~mm} \mathrm{Hg}$ and home $\mathrm{BP}$, $<125 / 75 \mathrm{~mm} \mathrm{Hg} .{ }^{14}$ However, no clinical assessment has yet investigated whether local physicians and hospital-based cardiologists achieve these optimal BP control targets using antihypertensive

${ }^{1}$ Cardiovascular Division, Institute of Clinical Medicine, Graduate School of Comprehensive Human Sciences, University of Tsukuba, Tsukuba, Japan; ${ }^{2}$ Department of Cardiology, Tokyo Medical University Ibaraki Medical Center, Ibaraki, Japan; ${ }^{3}$ Department of Cardiology, Yuai Memorial Hospital, Ibaraki, Japan; ${ }^{4}$ Sakuradai Doi Clinic, Ibaraki, Japan; ${ }^{5}$ Nakano Heart Clinic, Ibaraki, Japan and ${ }^{6}$ Kinunomachi Clinic, Ibaraki, Japan

Correspondence: Dr A Sato, Cardiovascular Division, Institute of Clinical Medicine, Graduate School of Comprehensive Human Sciences, University of Tsukuba, 1-1-1 Tennodai, Tsukuba, Ibaraki 305-8558, Japan.

E-mail: asato@md.tsukuba.ac.jp

Received 2 April 2010; revised 20 June 2010; accepted 8 July 2010; published online 7 October 2010 
treatment in clinical practice. Therefore, we surveyed the current status of BP control and antihypertensive therapy in patients receiving treatment for hypertension in 101 clinics and hospitals in Ibaraki Prefecture.

\section{METHODS}

\section{Study design}

The Ibaraki Hypertension Assessment Trial (I-HAT) was a multicenter crosssectional study involving 101 clinics and hospitals in Ibaraki Prefecture, Japan. Patients were recruited by general physicians and hospital-based cardiologists. Inclusion criteria were as follows: (1) primary hypertension defined by the recipient of antihypertensive treatment or, in the absence of treatment, by office BP values $>140 / 90 \mathrm{~mm} \mathrm{Hg}$ measured on two separate occasions; and (2) both office BP and morning home BP measurements performed with a sphygmomanometer. The data were collected on a case report form during the period October 2008 to March 2009. Office and home BP were recorded, as well as any antihypertensive treatments. Demographic and medical history characteristics including age, sex, body mass index, presence of DM, presence of dyslipidemia, presence of hyperuricemia, CKD, history of cardiovascular events (myocardial infarction, angina pectoris, stroke and heart failure) and peripheral artery disease were recorded. Written informed consent was obtained from all patients, and the study protocol was approved by our institutional review board.

The enrolled patients were divided into three groups according to the JSH 2009 Guidelines. Group A included high-risk patients with hypertension who had at least one of the following risk factors: (1) DM, (2) CKD or (3) history of myocardial infarction. Group B included hypertensive patients $<65$ years old without the above risk factors (defined as non-high-risk hypertensive patients). Group C included hypertensive patients $\geqslant 65$ years old without the above risk factors. According to JSH (2009), the target for control of office BP was <130/ $80 \mathrm{~mm} \mathrm{Hg}$ and for home BP was $<125 / 75 \mathrm{~mm} \mathrm{Hg}$ in Group A. In Group B, the target office BP was $<130 / 85 \mathrm{~mm} \mathrm{Hg}$ and the target home BP was $<125 / 80 \mathrm{~mm} \mathrm{Hg}$. In Group C, the target office BP was $<140 / 90 \mathrm{~mm} \mathrm{Hg}$ and the target home BP was $<135 / 85 \mathrm{~mm} \mathrm{Hg}$. The degree of office and morning home BP control was divided into four groups according to the following criteria (Table 1): (1) good control, (2) MHT, (3) white-coat hypertension and (4) poor control. The rate of achieving target home BP control in the morning, during the day and overnight was assessed in Group A $(<125 / 75 \mathrm{~mm} \mathrm{Hg})$, in Group B $(<125 / 80 \mathrm{~mm} \mathrm{Hg})$ and in Group C $(<135 / 85 \mathrm{~mm} \mathrm{Hg})$. In this analysis, the white-coat hypertension group included treated patients with uncontrolled BP status only under office settings. Similarly, the MHT group included those with masked uncontrolled hypertension that would represent uncontrolled BP status masked by the use of home BP measurement alone. These concepts are consistent with those used in previous studies ${ }^{10,11}$ and are based on previous reports showing that an insufficient duration of action for antihypertensive drugs represents an important factor in causing higher ambulatory or home BP values compared with office BP. ${ }^{15}$

The high dose of angiotensin receptor blocker (ARB) given was candesartan administered orally at $12 \mathrm{mg} /$ day, varsartan at $160 \mathrm{mg} /$ day and telmisartan at $160 \mathrm{mg} /$ day. The high dose of calcium channel blocker (CCB) given was amlodipine administered orally at $10 \mathrm{mg} /$ day, nifedipine at $80 \mathrm{mg} /$ day and alzenidipine at $16 \mathrm{mg} /$ day.

\section{Statistical analysis}

All data are expressed as the mean \pm s.d. or median and interquartile range. Comparisons of categorical variables between groups were performed by the $\chi^{2}$-test. Comparisons of continuous variables were analyzed by one-way analysis of variance or Kruskal-Wallis test. $P$-values less than 0.05 were considered significant. All probability values are considered significant when $<0.05$.

\section{RESULTS}

\section{Patient characteristics}

We surveyed 2435 patients from 101 clinics and hospitals. Those who had a missing home BP value $(n=98)$ were excluded from the analysis. A total of 2337 patients were included in this analysis, with 892 in Group A, 586 in Group B and 859 in Group C. The baseline clinical characteristics of the patients are summarized in Table 2. Age, history of angina pectoris and presence of arrhythmia were reported significantly more in Group A than in Group B. Age and presence of arrhythmia were observed significantly more in Group $\mathrm{C}$ than in Group A, whereas male gender and higher body mass index were observed significantly more in Group A than in Group C. Age, history of stroke and presence of arrhythmia were observed significantly more in Group C than in Group B. Daytime home BP was more frequently measured in Group B than in Group A, and evening home BP was more frequently measured in Group $\mathrm{C}$ than in Group A.

\section{Prescription of antihypertensive drugs}

Among the 2337 treated hypertensive patients, ARB were prescribed in $73.4 \%$ of patients and CCB in $64.1 \%$ of patients. ARBs were prescribed less frequently in Group B than in Group A and Group C. A detailed prescription of antihypertensive drugs is shown in Table 3. A mean of $1.8 \pm 1.0$ antihypertensive drugs per patient was prescribed, with $35.8 \%$ of all patients receiving monotherapy, $40 \%$ receiving two antihypertensives, $14.7 \%$ receiving three and $5.6 \%$ receiving more than four kinds of drugs. Lifestyle modification alone was used in $3.9 \%$ of patients. In regards to monotherapy, ARBs were more frequently prescribed in Group A than other groups (Group A, 64.8\%; Group B, 55.2\%; Group C, 55.7\%; $P<0.05$ ), while CCBs were less frequently prescribed in Group $A$ than other groups (Group A, 27.7\%; Group B, 36.2\%; Group C, 35.5\%; $P<0.001$ ). The most frequent combination of drugs was $\mathrm{ARB}+\mathrm{CCB}$ followed by $\mathrm{ARB}+$ a diuretic.

\section{Systolic and diastolic BP at the office and at home}

Office and home systolic and diastolic BP values are shown in Table 4. Systolic and diastolic office BP levels and home morning BP levels were similar among the three groups. Systolic and diastolic morning BP was significantly lower than office BP among all groups. The changes

Table 1 Definition and control status of office and home BP

\begin{tabular}{llll}
\hline & Good control & Masked hypertension & White coat hypertension \\
\hline Group A & Office BP $<130 / 80 \mathrm{~mm} \mathrm{Hg}$ & Office BP $<130 / 80 \mathrm{~mm} \mathrm{Hg}$ & Office BP $\geqslant 130 / 80 \mathrm{~mm} \mathrm{Hg}$ \\
& Home BP $<125 / 75 \mathrm{~mm} \mathrm{Hg}$ & Home BP $\geqslant 125 / 75 \mathrm{~mm} \mathrm{Hg}$ & Home BP $<125 / 75 \mathrm{~mm} \mathrm{Hg}$ \\
Group B & Office BP $<130 / 85 \mathrm{~mm} \mathrm{Hg}$ & Office BP $<130 / 85 \mathrm{~mm} \mathrm{Hg}$ & Office BP $\geqslant 130 / 85 \mathrm{~mm} \mathrm{Hg}$ \\
& Home BP $<125 / 80 \mathrm{~mm} \mathrm{Hg}$ & Home BP $\geqslant 125 / 80 \mathrm{~mm} \mathrm{Hg}$ & Home BP $<125 / 80 \mathrm{~mm} \mathrm{Hg} \quad$ Office BP $\geqslant 130 / 85 \mathrm{~mm} \mathrm{Hg} \quad$ Home BP $\geqslant 125 / 80 \mathrm{~mm} \mathrm{Hg} \quad$ Office BP $\geqslant 140 / 90 \mathrm{~mm} \mathrm{Hg}$ \\
Group C & Office BP $<140 / 90 \mathrm{~mm} \mathrm{Hg}$ & Office BP $<140 / 90 \mathrm{~mm} \mathrm{Hg}$ & Home BP $<135 / 85 \mathrm{~mm} \mathrm{Hg}$
\end{tabular}

Abbreviation: BP, blood pressure. 
Table 2 Clinical characteristics of the patients

\begin{tabular}{|c|c|c|c|c|}
\hline & $A / /(\mathrm{n}=2337)$ & Group A $(\mathrm{n}=892)$ & Group $B(\mathrm{n}=586)$ & Group C $(\mathrm{n}=589)$ \\
\hline Age (yrs) & $67.3 \pm 10.6$ & $69.1 \pm 10.7$ & $56.1 \pm 6.5^{\star \star *}$ & $73.0 \pm 5.8^{\# \# \#,{ }^{* * *}}$ \\
\hline Male (\%) & 47.0 & 52.5 & 47.6 & $41.0^{\#,{ }^{* * *}}$ \\
\hline $\mathrm{BMI}$ & $24.2 \pm 5.0$ & $24.8 \pm 6.2$ & $24.0 \pm 4.5^{* *}$ & $23.7 \pm 3.6^{* * *}$ \\
\hline Diabetes (\%) & 19.4 & 50.8 & 0 & 0 \\
\hline CKD (\%) & 24.3 & 63.8 & 0 & 0 \\
\hline Dyslipidemia (\%) & 32.6 & 38.2 & 30.4 & 28.4 \\
\hline Hyperuretemia (\%) & 1.6 & 2.1 & 1.5 & 1.2 \\
\hline Previous stroke (\%) & 2.7 & 1.5 & 3.6 & 2.8 \\
\hline Previous MI (\%) & 2.6 & 6.7 & 0 & 0 \\
\hline Angina pectoris (\%) & 7.5 & 9.0 & $5.8^{*}$ & 7.1 \\
\hline Arrythmia (\%) & 6.2 & 6.7 & $3.2^{* *}$ & $7.8^{\# \# \#}$ \\
\hline Heart failure (\%) & 1.7 & 1.9 & 1.4 & 1.6 \\
\hline PAD (\%) & 0.4 & 0.9 & 0.2 & 0.1 \\
\hline BP measurement at Daytime/nighttime (\%) & $29.1 / 64.9$ & $26.4 / 61.3$ & $32.8^{* *} / 65.0$ & $29.3 / 68.6^{* *}$ \\
\hline ARB & 73.4 & 77.8 & $69.6^{* * *}$ & $71.4^{* *}$ \\
\hline ACE-I & 7.7 & 8.2 & 6.8 & 7.7 \\
\hline Ca-blockers & 64.1 & 63.7 & 64.3 & 64.5 \\
\hline Diutretics & 15.4 & 14.9 & 14.3 & 16.6 \\
\hline$\beta$-Blockers & 14.5 & 15.4 & 14.0 & 13.9 \\
\hline$\alpha$-Blockers & 4.9 & 3.9 & 5.5 & 5.6 \\
\hline Other drugs & 3.7 & 2.8 & 3.8 & 4.5 \\
\hline
\end{tabular}

Abbreviatuins: ACE-I, angiotensin converting enzyme inhibitor; ARB, angiotensin receptor blocker; BMI, body mass index; BP, blood pressure; CKD, chronic kidney disease; MI, myocardial infarction; PAD, peripheral artery disease.

${ }^{*} P<0.05,{ }^{* *} P<0.01,{ }^{* * *} P<0.001$ vs. Group A; ${ }^{\#} P<0.05,{ }^{\# \#} P<0.001$ vs. Group B.

Table 3 Antihypertensive drugs prescribed for monotherapy and combination therapy

\begin{tabular}{|c|c|c|c|c|}
\hline & Al/ $(\mathrm{n}=2337)$ & Group $A(\mathrm{n}=892)$ & Group $B(\mathrm{n}=586)$ & Group $C(\mathrm{n}=859)$ \\
\hline Number of prescription & $1.8 \pm 1.0$ & $1.9 \pm 0.9$ & $1.8 \pm 1.0$ & $1.8 \pm 1.0$ \\
\hline No prescription & $90(3.9 \%)$ & $25(2.8 \%)$ & $28(4.8 \%)^{*}$ & $37(4.3 \%)$ \\
\hline Monotherapy & $837(35.8 \%)$ & $318(35.7 \%)$ & $210(35.8 \%)$ & 309 (36.0\%) \\
\hline ARB & $494(59.0 \%)$ & $206(64.8 \%)$ & $116(55.2 \%)^{*}$ & $172(55.7 \%)^{*}$ \\
\hline ACE-I & $27(3.2 \%)$ & $10(3.1 \%)$ & $8(3.8 \%)$ & 9 (2.9\%) \\
\hline Ca-blockers & $273(32.6 \%)$ & $88(27.7 \%)$ & $76(36.2 \%)^{*}$ & $109(35.3 \%)^{*}$ \\
\hline Diuretics & $9(1.1 \%)$ & $0(0.0 \%)$ & $1(0.5 \%)$ & $8(2.6 \%)$ \\
\hline$\beta$-Blockers & $28(3.3 \%)$ & $13(4.1 \%)$ & $7(3.3 \%)$ & $8(2.6 \%)$ \\
\hline Other drugs & $6(0.7 \%)$ & $1(0.3 \%)$ & $2(1.0 \%)$ & $3(1.0 \%)$ \\
\hline Two drugs & $934(40.0 \%)$ & $361(40.5 \%)$ & $245(41.8 \%)$ & $328(38.2 \%)$ \\
\hline ARB+Ca-blockers & $670(71.7 \%)$ & 263 (72.9\%) & 165 (67.3\%) & 242 (73.8\%) \\
\hline ARB+diuretics & 72 (7.7\%) & $24(6.6 \%)$ & $19(7.8 \%)$ & $29(8.8 \%)$ \\
\hline Ca-blockers+diuretics & $15(1.6 \%)$ & $6(1.7 \%)$ & $6(2.4 \%)$ & $3(1.0 \%)$ \\
\hline Other combination & $177(19.0 \%)$ & $68(18.8 \%)$ & $55(22.4 \%)$ & $54(16.5 \%)$ \\
\hline Three drugs & $344(14.7 \%)$ & $138(15.5 \%)$ & $74(12.6 \%)$ & $132(15.4 \%)$ \\
\hline ARB+Ca-blockers+diuretics & $118(34.3 \%)$ & $47(34.1 \%)$ & $31(41.9 \%)$ & $40(30.3 \%)$ \\
\hline Other combination & $226(65.7 \%)$ & $91(65.9 \%)$ & $43(58.1 \%)$ & $92(69.7 \%)$ \\
\hline More than four drugs & $132(5.6 \%)$ & $50(5.6 \%)$ & $29(4.9 \%)$ & $53(6.2 \%)$ \\
\hline
\end{tabular}

Abbreviations: ACE-I, angiotensin converting enzyme inhibitor; ARB, angiotensin receptor blocker. ${ }^{*} P<0.05$ vs. Group A.

between night time BP and morning BP are shown in Figure 1. Systolic and diastolic BP increased $7.5 \mathrm{~mm} \mathrm{Hg}(6.2 \%)$ and $5.4 \mathrm{~mm} \mathrm{Hg}(7.9 \%)$ from night time to morning, respectively, in all groups.

\section{Office BP control rates}

Figure 2 shows the office BP control rates. Office BP control was achieved in $26.9 \%$ of Group A patients, $25.6 \%$ of Group B patients (non-high-risk hypertensive patients $<65$ years old) and $57.3 \%$ of Gorup $C$ patients $(\geqslant 65$ years old) $(P<0.001)$. The percentage of patients achieving the target $\mathrm{BP}$ of daytime, night time, and morning was significantly higher in Group $C$ than in the other groups $(P<0.001)$. Figure 3 shows the number of medications required to achieve the target office BP. A combination of more than two medications was prescribed in approximately $60 \%$ of patients. 
Table 4 Systolic and diastolic blood pressure levels measured at office and morning home

\begin{tabular}{|c|c|c|c|c|}
\hline & All $(\mathrm{n}=2337)$ & Group A $(\mathrm{n}=892)$ & Group $B(\mathrm{n}=586)$ & Group C $(\mathrm{n}=859)$ \\
\hline Morning homed SBP & $134.9 \pm 12.4^{* *}$ & $133.9 \pm 11.3^{* *}$ & $136.0 \pm 12.3^{* *}$ & $135.2 \pm 13.4^{* *}$ \\
\hline Morning homed DBP & $78.4 \pm 9.3^{* * *}$ & $78.1 \pm 9.1^{* * *}$ & $78.7 \pm 11.0^{* * *}$ & $78.4 \pm 9.3^{* * *}$ \\
\hline
\end{tabular}

Abbreviations: DBP, diastolic blood pressure; SBP, systolic blood pressure.

${ }^{* *} P<0.01,{ }^{* * *} P<0.001$ vs. office.
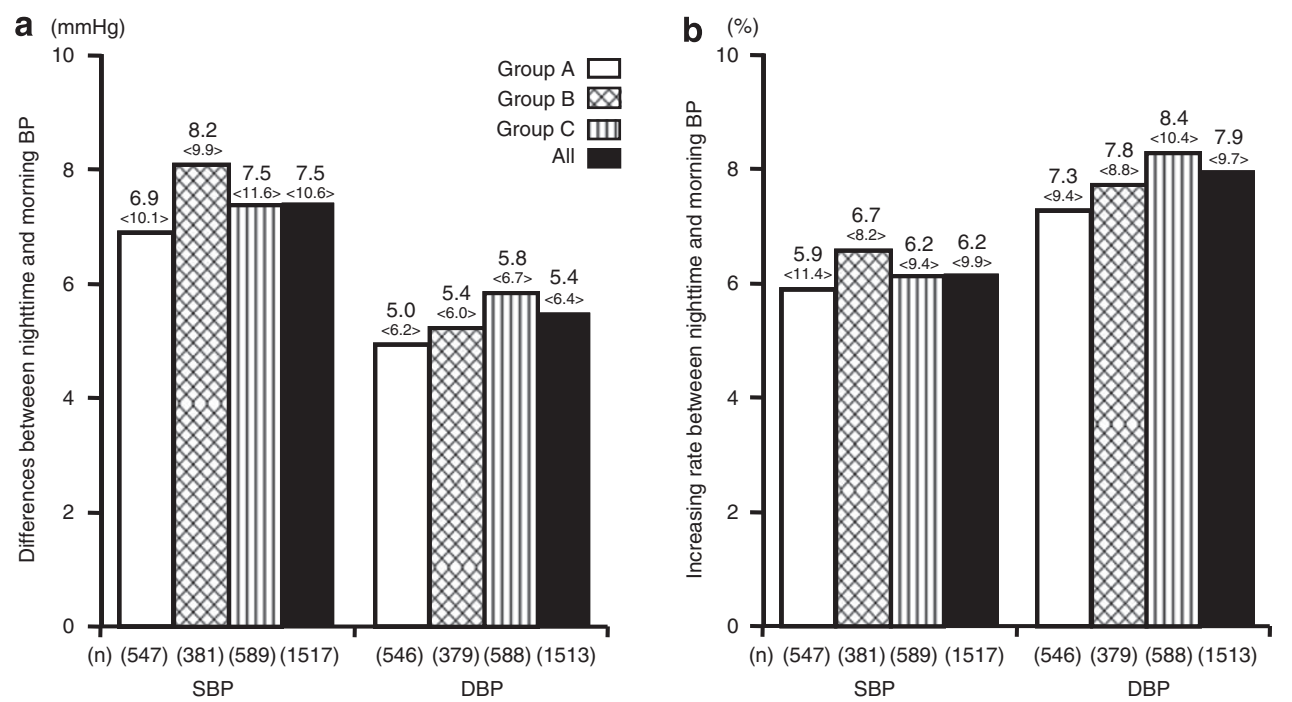

Figure 1 Differences (a) and increasing rates (b) between night time and morning BP. Group A: hypertensive patients with DM, CKD or history of myocardial infarction (MI). Group B: hypertensive patients less than 65 years old without DM, CKD or history of MI. Group C: hypertensive patients over 65 years old without DM, CKD or history of MI. SBP, systolic blood pressure (BP); DBP, diastolic BP; mean \pm s.d.

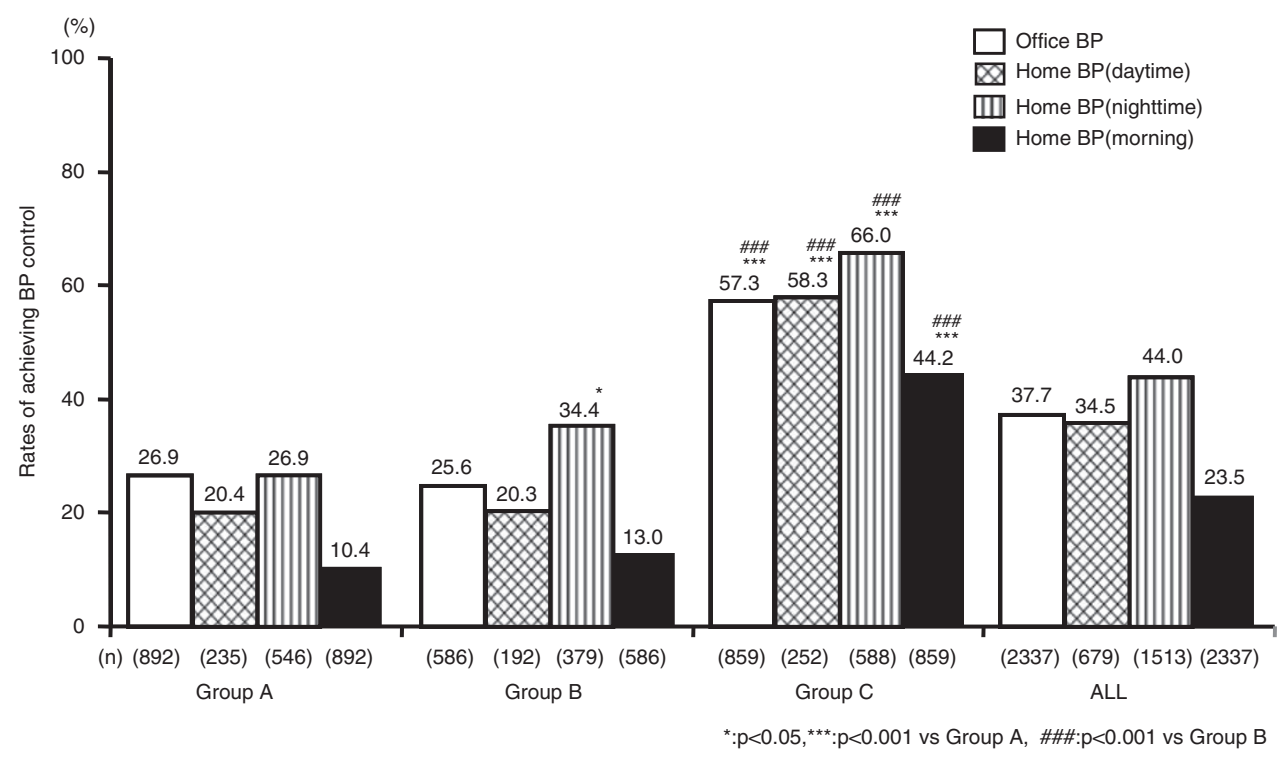

Figure 2 Rates of achieving BP control in Groups A, B and C. Groups A, B and C as in Figure 1. ${ }^{*} P<0.05, * * * P<0.001$ vs. Group A, \#\#\# $P<0.001$ vs. Group B.

We evaluated the dose of ARB and CCB, which was the most frequent combination of antihypertensives prescribed in patients achieving their target BP (Figure 4). A high dose of ARB or CCB was most frequently prescribed in Group A. Group A patients on this high dose of $A R B$ or CCB were more likely to achieve the target office BP compared with Groups B and C. 


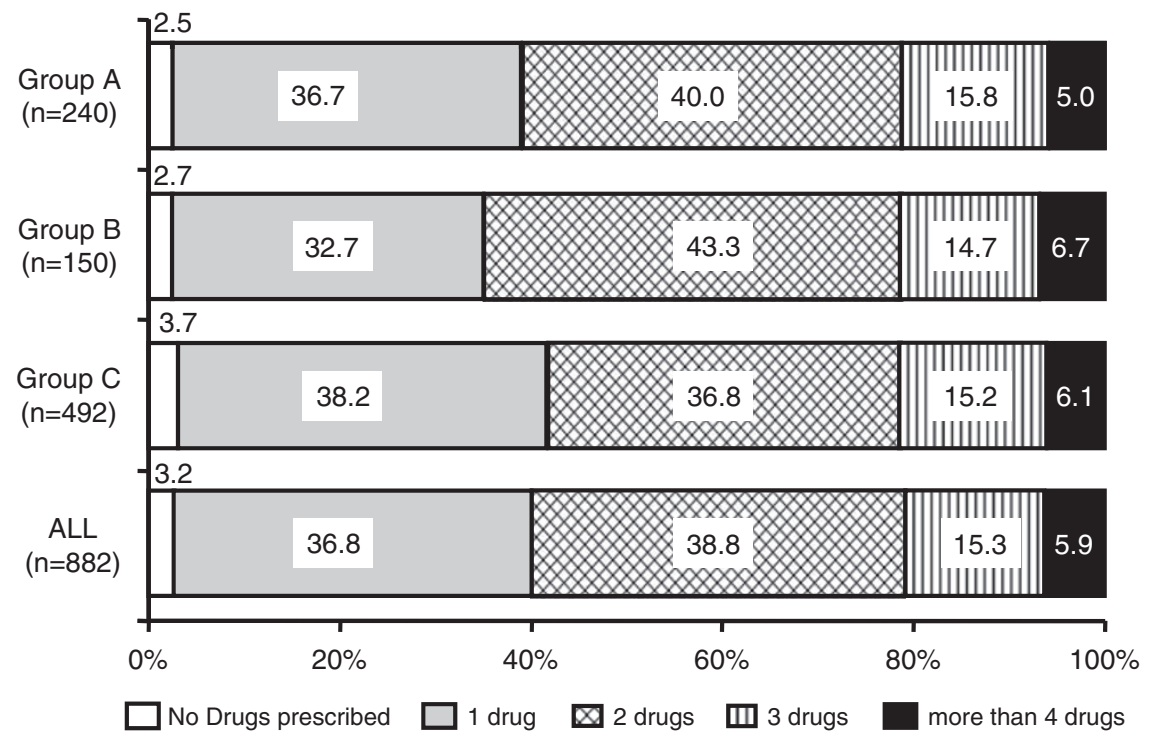

Figure 3 Number of antihypertensives prescribed in patients achieving office BP control. Groups A, B and C as in Figure 1.

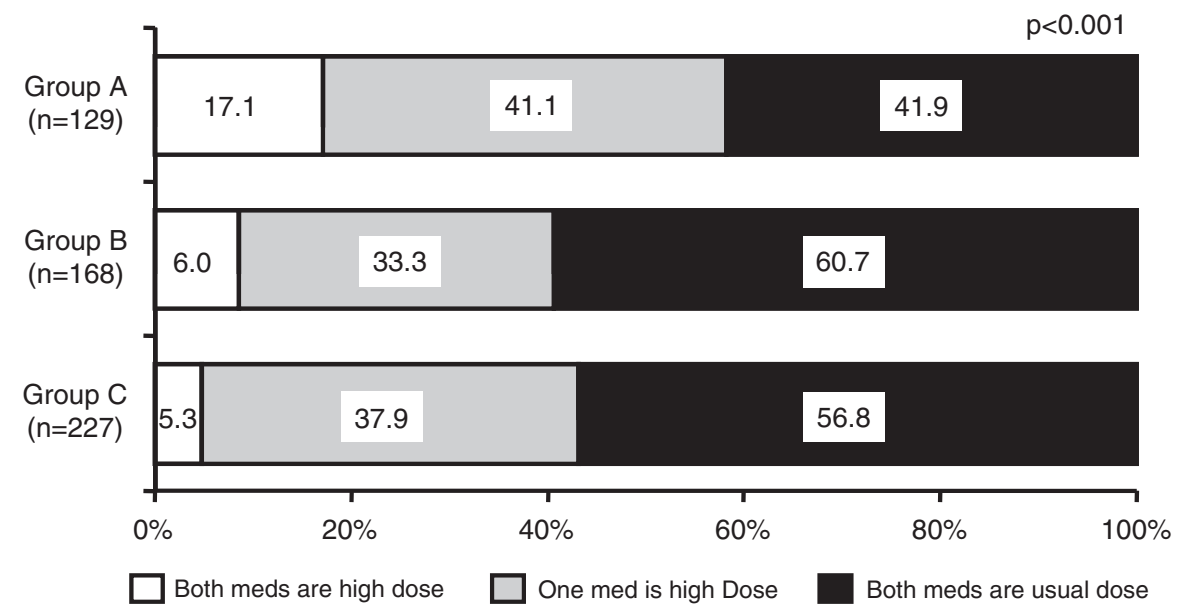

Figure 4 Relationship between dose of calcium antagonist and ARB and status of office BP control. Groups A, B and C as in Figure 1 . P<0.001 vs. Group $\mathrm{B}$ and $\mathrm{C}$.

\section{Status of BP control and incidence of MHT}

Office and home BP control values are shown in Figure 5. Good BP control was achieved in $13.3 \%$, with $24.4 \%$ showing MHT, $10.2 \%$ showing white-coat hypertension and $52.1 \%$ showing poor control. The incidence of good control was higher in Group C than in the other groups $(4.5 \%$ in Group A, 3.6\% in Group B and $29.1 \%$ in Group C; $P<0.001)$. There were no differences in the incidence of MHT among the three groups. Figure 6 shows office and home BP control values using systolic BP alone and diastolic BP alone. The incidence of good control was higher in Group $C$ than in the other groups for both systolic and diastolic BP. Systolic BP control was significantly poorer than diastolic BP control among all groups. There were no differences in age and sex effects on the status of BP control among all groups (Figure 7, Table 5).

\section{DISCUSSION}

This study had several important findings. First, our study demonstrates that office BP control was achieved in $26.9 \%$ of high-risk hypertensive patients, $25.6 \%$ of non-high-risk hypertensive patients $<65$ years old, and $57.3 \%$ of non-high-risk hypertensive patients $\geqslant 65$ years old. The percentage of patients attaining a target BP was higher in the I-HAT study than in previous reports. Second, a combination of more than two antihypertensive drugs and a high dose of an ARB or a CCB was frequently prescribed in high-risk hypertensive patients to achieve the target office BP. Despite the fact that the target BP should be lower in high-risk hypertensive patients, the absolute BP value and number of medications are similar to the other groups. Therefore, it is very important to intensively measure and achieve the target home BP in addition to controlling the office BP according to JSH (2009).

Previous studies have demonstrated that intensive BP control decreases the risk of cardiovascular events. ${ }^{16-18}$ The CASE-J trial showed that office BP control within $140 / 90 \mathrm{~mm} \mathrm{Hg}$ reduces the risk of cardiovascular events in spite of age. Furthermore, strict BP control $(<130 / 80 \mathrm{~mm} \mathrm{Hg})$ was associated with a reduced risk of cardiovascular events in hypertensive patients with DM, CKD or left ventricular hypertrophy. ${ }^{19,20}$ The JSH 2009 Guidelines recommend 


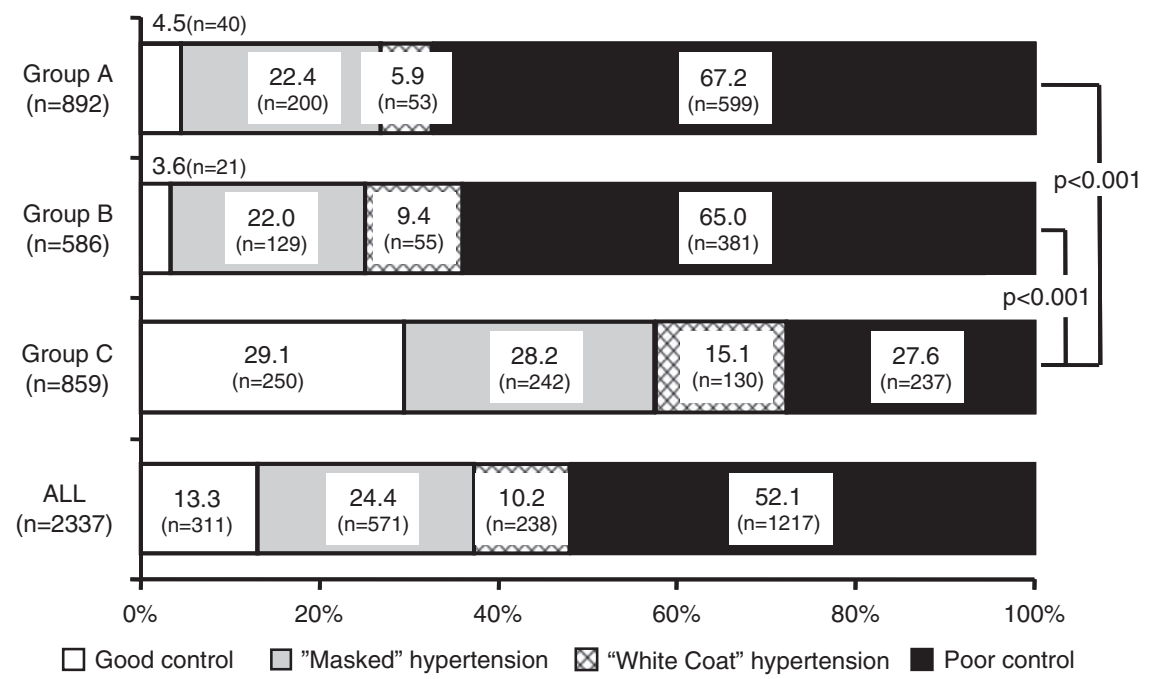

Figure 5 Status of office and home BP control. Groups A, B and C as in Figure 1. $P<0.001$ compared with Group A and Group B.

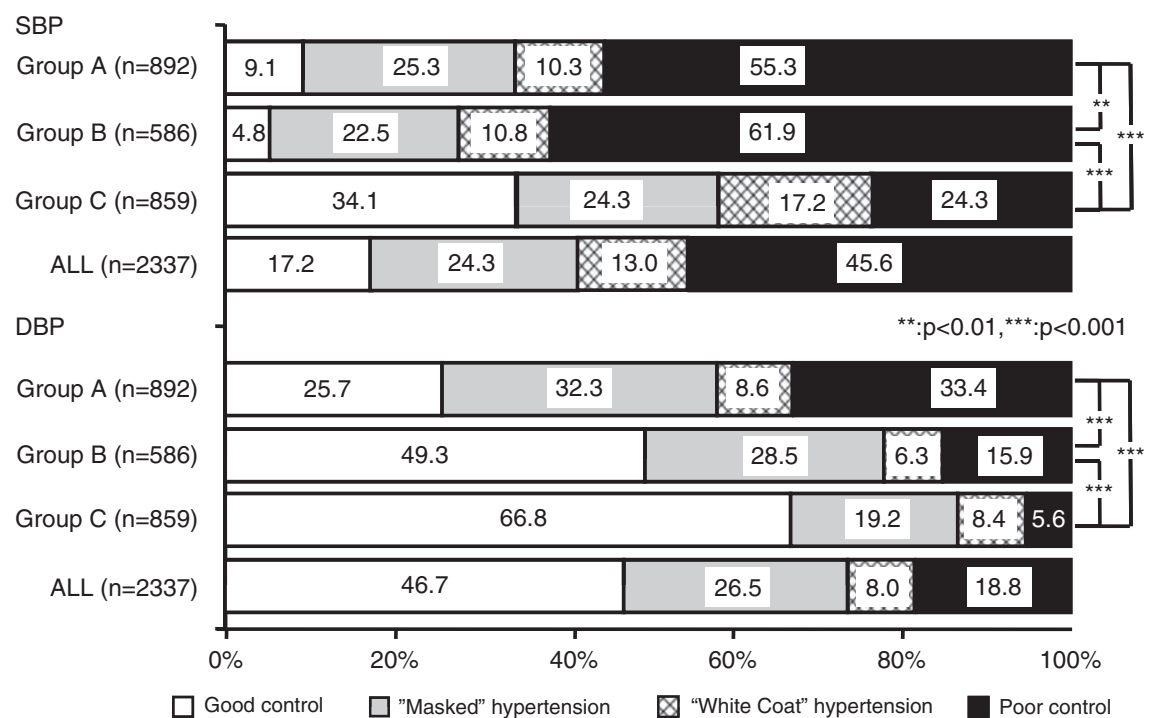

Figure 6 Status of systolic and diastolic pressure control at the office and at home. Groups A, B and C as in Figure $1 .{ }^{* *} P<0.01,{ }^{* * *} P<0.001$.

that office BP be $<130 / 80 \mathrm{~mm} \mathrm{Hg}$ and home BP be $<125 / 75 \mathrm{~mm} \mathrm{Hg}$ in high-risk patients with $\mathrm{DM}, \mathrm{CKD}$ and previous myocardial infarction. ${ }^{14}$ In the I-HAT study, home and office BP levels were similar among high-risk hypertensive patients and the other hypertensive patients, and slightly lower in high-risk hypertensive patients. However, the rate of achieving the target BP was markedly lower in highrisk hypertensive patients and other hypertensive patients $<65$ years old compared with the hypertensive patients $\geqslant 65$ years old. It seems as if this result depended on the target BP values among the three groups. In addition, despite the fact that target BP should be lower in high-risk hypertensive patients, the absolute BP value and the number of medications are almost the same. Despite the fact that guidelines recommend intensive care in high-risk patients, there was no difference in the treatment of these groups in this study. Although various pharmacological treatment options exist, BP control was suboptimal and major efforts are necessary to improve patients' awareness and compliance, as well as physicians' adherence to treatment guidelines.
In the I-HAT study, office BP control was achieved in $45.7 \%$ of all patients, $26.9 \%$ of high-risk hypertensive patients, $25.6 \%$ of non-highrisk hypertensive patients $<65$ years old and $57.3 \%$ of patients $\geqslant 65$ years old. Previous reports demonstrate that office BP control was achieved in approximately $20 \%$ of hypertensive patients with $\mathrm{DM}^{18,21}$ and $38 \%$ of hypertensive patients without DM. ${ }^{21}$ The percentage of patients attaining a target BP was higher in the I-HAT study than in previous reports. Mori et al. reported that monotherapy was prescribed in $62.3 \%$ of patients and office BP control was achieved in approximately $11.3 \%$ of hypertensive patients with DM and $32.5 \%$ of hypertensive patients without DM. ${ }^{22}$ The stroma study demonstrated that among the treated hypertensive patients, $11.8 \%$ did not reach the target BP $(<140 / 90 \mathrm{~mm} \mathrm{Hg})$, and $67 \%$ had monotherapy. ${ }^{23}$ There was a significant correlation between the number of antihypertensives prescribed and the efficacy of lowering $\mathrm{BP}^{24}$ In the I-HAT study, a combination of more than two antihypertensive drugs was prescribed in more than $60 \%$ of hypertensive patients to achieve the target office 


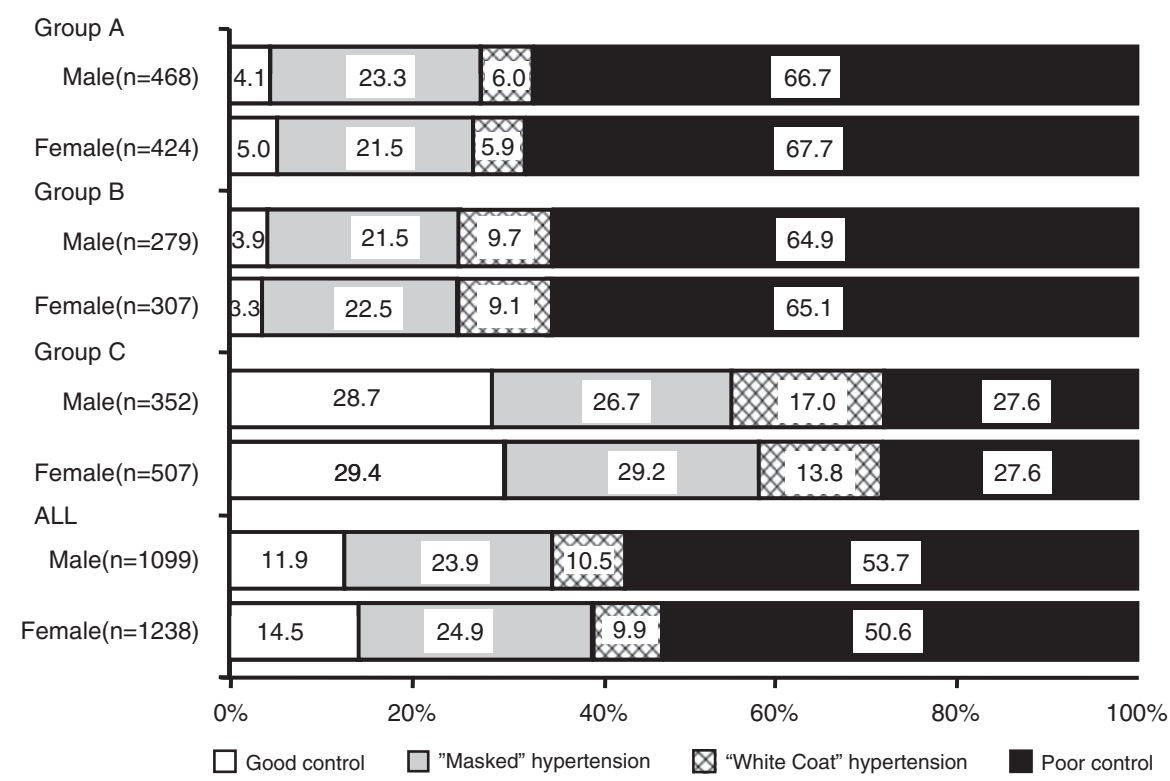

Figure 7 Status of office and home BP control according to gender. Groups A, B and C as in Figure 1.

Table 5 Mean age among three groups by control status of office and home BP

\begin{tabular}{lllll}
\hline & $\begin{array}{c}\text { Good } \\
\text { control }\end{array}$ & $\begin{array}{c}\text { Masked } \\
\text { hypertension }\end{array}$ & $\begin{array}{c}\text { White coat } \\
\text { hypertension }\end{array}$ & $\begin{array}{c}\text { Poor } \\
\text { control }\end{array}$ \\
\hline Group A & $68.0 \pm 12.1$ & $68.4 \pm 10.7$ & $67.1 \pm 10.5$ & $69.6 \pm 10.6$ \\
Group B & $57.5 \pm 6.1$ & $56.4 \pm 5.9$ & $56.8 \pm 5.8$ & $55.8 \pm 6.8$ \\
Group C & $72.8 \pm 5.4$ & $73.1 \pm 6.1$ & $73.2 \pm 6.8$ & $73.1 \pm 5.5$ \\
All & $71.2 \pm 7.8$ & $67.7 \pm 10.2$ & $68.2 \pm 10.1$ & $65.9 \pm 11.1$ \\
\hline
\end{tabular}

BP. In addition, a high dose of ARB or CCB was frequently prescribed in hypertensive patients to achieve the target office BP. Therefore, prescription of multiple antihypertensive medications and high-dose therapy is recommended for achieving target office BP.

Previous studies demonstrate that MHT is associated with a significantly greater risk of stroke and cardiovascular mortality. ${ }^{10,11}$ In the I-HAT study, there were no differences in the incidence of MHT (24.4\%) among the three groups. This suggests that controlling morning BP is more difficult than controlling office BP in clinical practice. The JSH 2009 demonstrate that obesity, DM, cardiovascular disease and use of short-acting antihypertensive drugs insufficient to control BP were associated with an increased risk of MHT. In the IHAT study, ARB was prescribed in $59 \%$ of such high-risk patients. There have been many reports regarding the differences in the duration of action of ARBs. ${ }^{25-27}$ Candesartan is superior to losartan in reducing systolic ambulatory BP and controlling systolic, as well as diastolic, ambulatory BP on the day of a missed dose. Candesartan exhibits tight binding and a slow dissociation rate from the AT1 receptor. This finding may be influenced by differences in the duration of action of individual ARBs. Therefore, further comparisons of the incidence of MHT and duration of action of ARB are necessary to provide new clinical and therapeutic insights.

The JSH 2009 recommends intensively using ARB or ACE-I in hypertensive patients with DM and CKD. In the I-HAT study, ARB was prescribed in $77.8 \%$ of Group A patients and as monotherapy in $64.8 \%$ of patients. This finding demonstrates that many clinicians intensively prescribed $\mathrm{ARB}$ as a first choice for high-risk hypertensive patients with DM and CKD according to the JSH 2009 recommendation. However, only $13.3 \%$ of all patients achieved their target BP, with 24.4\% showing MHT and $52.1 \%$ showing poor control. Physicians should treat hypertension more intensively to achieve the target BP.

The current study has some limitations. First, the I-HAT study was a cross-sectional study at one point of time in Ibaraki Prefecture. Second, morning BP was not measured in an ambulatory setting.

\section{CONCLUSION}

The I-HAT study demonstrated that physicians should treat hypertension more intensively to achieve the target office BP by using a combination of more than two kinds of hypertensive drugs and a high dose. Moreover, it is important to intensively teach hypertensive patients the clinical importance of achieving home BP targets, in addition to office BP targets.

\section{CONFLICT OF INTEREST}

The authors declare no conflict of interest.

\section{ACKNOWLEDGEMENTS}

We thank the following physicians who participated in the I-HAT study and made this work possible; HAT investigators: A Miyamoto, A Atsumi, A Katoh, A Imamura, A Yamazaki, A Goto, B Niho, D Abe, F Kamezaki, F Makabe, H Nakagawa, H Kobayashi, H Asakura, H Unno, H Kikuchi, H Nakajima, H Torigoe, H Tanaka, H Ebata, I Hanyuu, J Miyamoto, J Munakata, K Matsumaru, K Goshima, K Ishii, K Frushou, K Sugiura, K Narushima, K Taya, K Kawashima, M Kenmochi, M Yamaki, M Kaneko, M Endo, M Katou, M Komatsuzaki, M Sonobe, M Saitou, M Kanou, M Kobayashi, M Mizutani, M Ishii, M Ogura, M Kenjou, M Sasaki, M Noritake, M Itou, M Satoh, M Tokoi, M Miyazaki, M Hiyama, M Toyama, M Kuno, M Kumagae, N Maeda, N Murakoshi, N Yamaguchi, N Matsukura, N Takeyasu, R Yamada, R Tachieda, R Sugaya, R Kawakami, S Ebata, S Abeta, S Satou, S Watanabe, S Nemoto, S Suzuki, S Yamaguchi, S Gotou, T Morimoto, T Watanabe, T Kurosawa, T Saitou, T Ayabe, T Yodonawa, T Koh, T Kasano, T Ohkubo, T Ishizu, T Nagano, T Kaizan, T Kawamoto, T Inaba, T Murata, T Tasaki, T Aoki, T Enomoto, W Njaman, Y Ishii, Y Iwamoto, Y Shimizu, Y Takagi, Y Kusama, Y Seo, Y Obara, Y Itou, Y Handa, Y Shiraishi, Y Watanabe, Y Azami, Y Arita, Y Saitou, Y Shimizu, Y Watanabe and Y Hatagawa. 
1 Nippon Data 80 Research Group. Impact of elevated blood pressure on mortality from all causes, cardiovascular diseases, heart disease and stroke among Japanese: 14 year follow-up of randomly selected population from Japanese -Nippon data 80-. J Hum Hypertens 2003; 17: 851-857.

2 Tanizaki Y, Kiyohara Y, Kato I, Iwamoto H, Nakayama K, Shinohara N, Arima H, Tanaka K, Ibayashi S, Fujishima M. Incidence and risk factors for subtypes of cerebral infarction in a general population: The Hisayama study. Stroke 2000; 31: 2616-2622.

3 Prospective Studies Collaboration. Age-specific relevance of usual blood pressure to vascular mortality: a meta-analysis of individual data for one million adults. Lancet 2002; 360: 1903-1913.

4 Lawes CM, Asia Pacific Cohort Studies Collaboration. Blood pressure and cardiovascular disease in the Asia Pacific region. J Hypertens 2003; 21: 707-716.

5 Wolf-Maier K, Cooper RS, Banegas JR, Giampaoli S, Hense HW, Joffres M, Kastarinen M, Poulter N, Primatesta P, Rodríguez-Artalejo F, Stegmayr B, Thamm M, Tuomilehto J, Vanuzzo D, Vescio F. Hypertension prevalence and blood pressure levels in 6 European countries, Canada, and the United States. JAMA 2003; 289: 2363-2369.

6 Tanizaki Y, Kiyohara Y, Kato I, Iwamoto H, Nakayama K, Shinohara N, Arima H, Tanaka K, Ibayashi S, Fujishima M. Incidence and risk factors for subtypes of cerebral infarction in a general population: The Hisayama study. Stroke 2000; 31: 2616-2622.

7 Staessen JA, Gasowski J, Wang JG, Thijs L, Hond ED, Boissel JP, Coope J, Ekbom T, Gueyffier F, Liu F, Kerlikowske K, Pocock S, Fagard RH. Risks of untreated and treated isolated systolic hypertension in the elderly: meta-analysis of outcome trials. Lancet 2000; 355: 865-872.

8 Staessen JA, Wang JG, Thijs L. Cardiovascular protection and blood pressure reduction: a meta-analysis. Lancet 2001; 358: 1305-1315.

9 Blood Pressure Lowering Treatment Trialists Collaboration. Effects of different bloodpressure-lowering regimens on major cardiovascular events: results of prospectivelydesigned overviews of randomized trials. Lancet 2003; 362: 1527-1545.

10 Ohkubo T, Kikuya M, Metoki H, Asayama K, Obara T, Hashimoto J, Totsune K, Hoshi H, Satoh H, Imai Y. Prognosis of 'Masked' hypertension and 'White-Coat' hypertension detected by 24-h ambulatory blood pressure monitoring 10-year follow-up from the Ohasama study. J Am Coll Cardiol 2005; 46: 508-515.

11 Bobrie G, Chatellier G, Genes N, Clerson P, Vaur L, Vaisse B, Menard J, Mallion JM. Cardiovascular prognosis of 'Masked Hypertension' detected by blood pressure self-measurement in elderly treated hypertensive patients. JAMA 2004; 291: $1342-1349$.

12 Ohkubo T, Imai Y, Tsuji I, Nagai K, Katoh J, Kikuchi N, Nishiyama A, Aihara A, Sekino M, Kikuya M, Ito S, Satoh H, Hisamichi S. Home blood pressure measurement has a stronger predictive power for mortality than does screening blood pressure measurement: a population-based observation in Ohasama Japan. J Hypertens 1998; 16: 971-975.

13 Sega R, Facchetti R, Bombelli M, Cesana G, Corrao G, Grassi G, Mancia G. Prognostic value of ambulatory and home blood pressures compared with office blood pressure in the general population: Follow-up results from the pressioni arteriose monitorate e loro associazioni (PAMELA) study. Circulation 2005; 111: 1777-1783.
14 Ogihara T, on behalf of The Japanese Society of Hypertension Committee for Guidelines for the Management of Hypertension. The Japanese society of hypertension guidelines for the management of hypertension (JSH 2009). Hypertens Res 2009; 32: 4-107.

15 Chonan K, Hashimoto J, Ohkubo T, Tsuji I, Nagai K, Kikuya M, Hozawa A, Matsubara M, Suzuki M, Fujiwara T, Araki T, Satoh H, Hisamichi S, Imai Y. Insufficient duration of action of antihypertensive drugs mediates high blood pressure in the morning in hypertensive population: the Ohasama study. Clin Exp Hypertens 2002; 24: 261-275.

16 The Heart Outcomes Prevention Evaluation Study Investigators. Effects of an angiotensin-converting-enzyme inhibitor, ramipril, on cardiovascular events in high-risk patients. N Engl J Med 2000; 342: 145-153.

17 Nissen SE, Tuzcu EM, Libby P, Thompson PD, Ghali M, Garza D, Berman L, Shi H, Buebendorf E, Topol EJ, for the CAMELOT Investigators. Effect of antihypertensive agents on cardiovascular events in patients with coronary heart disease and normal blood pressure. The CAMELOT Study: a randomized controlled trial. JAMA 2004; 292 : 2217-2226.

18 Kawamori R, Fujita T, Matsuoka T, Umemura S, Saito Y. Relation between cardiovascular complications blood pressure/blood glucose control in diabetic patients with hypertension receiving long-term candesartan cilexetil therapy: Challenge-DM study. Diabetes Res Clin Pract 2009; 83: 241-248.

19 Ogihara T, Nakao K, Fukui T, Fukiyama K, Fujimoto A, Ueshima K, Oba K, Shimamoto K, Matsuoka H, Saruta T, for the CASE-J trial group. The optimal target blood pressure for antihypertensive treatment in Japanese elderly patients with high risk hypertension: A Subanalysis of the candesartan antihypertensive survival evaluation in Japan (CASEJ) trial. Hypertens Res 2008; 31: 1595-1601.

20 Ogihara T, Saruta T, Rakugi H, Fujimoto A, Ueshima K, Yasuno S, Oba K, Takeda K, Higaki J, Nakao K, on behalf of the CASE-J trial group. Relationship between the achieved blood pressure and the incidence of cardiovascular events in Japanese hypertensive patients with complications: a sub-analysis of the CASE-J trial. Hypertens Res 2009; 32: 248-254.

21 Thoenes M, Neuberger H-R, Volpe M, Khan BV, Kirchl W, Bohm M. Antihypertensive drug therapy and blood pressure control in men and women: an international perspective. J Hum Hypertens 2010; 24: 336-344.

22 Mori H, Ukai H, Yamamoto H, Saitou S, Hirao K, Yamauchi M, Umemura S. Current status of antihypertensive prescription associated blood pressure control in Japan. Hypertens Res 2006; 29: 143-151.

23 Li C, Engström G, Hedblad B, Berglund G, Janzon L. Blood pressure control and risk of stroke: A population-based prospective cohort study. Stroke 2005; 36: 725-730.

24 Elliot WJ. Is fixed combination therapy appropriate for initial hypertension treatment. Curr Hypertens Reports 2002; 4: 278-285.

25 Anderson 0 , Neldam T. The antihypertensive effect tolerability of candesartan cilexetil a new generation angiotensin II antagonist in comparison with losartan. Blood Press 1998; 7: 53-59.

26 Oparil S, Williams D, Chrysant SG, Marbury TC, Neutel J. Comparative efficacy of olmesartan, Iosartan, valsartan, and Irbesartan in the control of essential hypertension. J Clin Hypertens 2001; 3: 283-291.

27 Smith DG, Matzek KM, Kempthorne-Rawson J. Dose response safety of telmisartan in patients with mild to moderate hypertension. J Clin Pharmacol 2000; 40: 1380-1390. 